\title{
CORRIGENDUM
}

\section{Safety, tolerability and sustained weight loss over 2 years with the once-daily human GLP-1 analog, liraglutide}

A Astrup, R Carraro, N Finer, A Harper, M Kunesova, MEJ Lean, L Niskanen, MF Rasmussen, A Rissanen, S Rössner, MJ Savolainen and L Van Gaal on behalf of the NN8022-1807 Investigators

International Journal of Obesity (2013) 37, 322; doi:10.1038/ijo.2012.192

Correction to: International Journal of Obesity (2012) 36, 843-854; doi:10.1038/ijo.2011.158

Since publication of this article the authors have noticed the following errors. The original article has not been amended with these corrections.

In the analysis of covariance analyses used in the paper, two different approaches were used in the model estimation of least square (LS) means. The estimated differences between treatment means and $P$-values were unchanged, and the conclusions of the paper were likewise unaffected. However, in one model, the LS means reflected the distribution of the factors in the data, that is, $30 / 70$ for gender, while the other model estimated the change as an equal contribution from each factor, for example, 50/50 for gender. Neither is incorrect, but the same approach should have been used throughout the paper. Three parameters were analysed using the model with LS means that reflected the distribution of factors in the model. These were: weight loss with nausea and/or vomiting, pulse and 2-year insulin data. The other model where LS means had an equal contribution from each factor was used in all other analyses and tables in the paper. In order to ensure that consistent estimates are presented throughout the paper, we have decided to apply the latter model to all analyses. This corrigendum has therefore been prepared to correct the analysis of covariance model used to analyse the above mentioned variables (weight loss with nausea and/or vomiting, pulse and 2-year insulin data) so the factors in the model have an equal contribution to the LS means.

The corrected section of text and the revised Figure $3 \mathrm{~b}$ are shown below. Text in bold denotes corrected text and strikethrough denotes the original text.

There is also an amendment to Supplementary Figure 3c, which can be viewed in the online version of this corrigendum.

\section{Safety and tolerability and quality of life}

Mean 1-year weight loss from randomization with liraglutide $3.0 \mathrm{mg}$ was $9.2 \mathrm{~kg} 10.0 \mathrm{~kg}$ for those with nausea and/or vomiting $(n=49)$ and $6.3 \mathbf{~ k g ~} 7.1 \mathrm{~kg}$ for those without $(n=43)$ (difference $2.9 \mathrm{~kg}$ (95\% confidence interval 0.5-5.3); $P=0.02$ ).

\section{b}

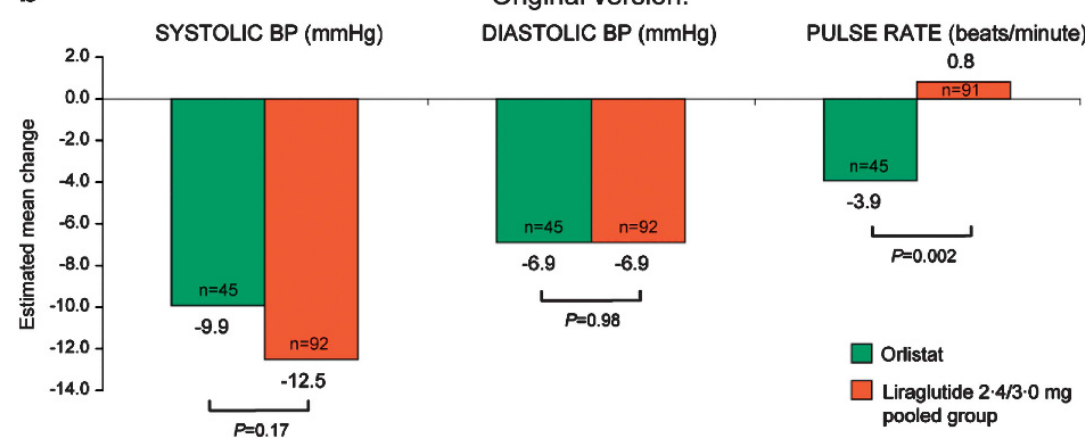

b

Revised version:

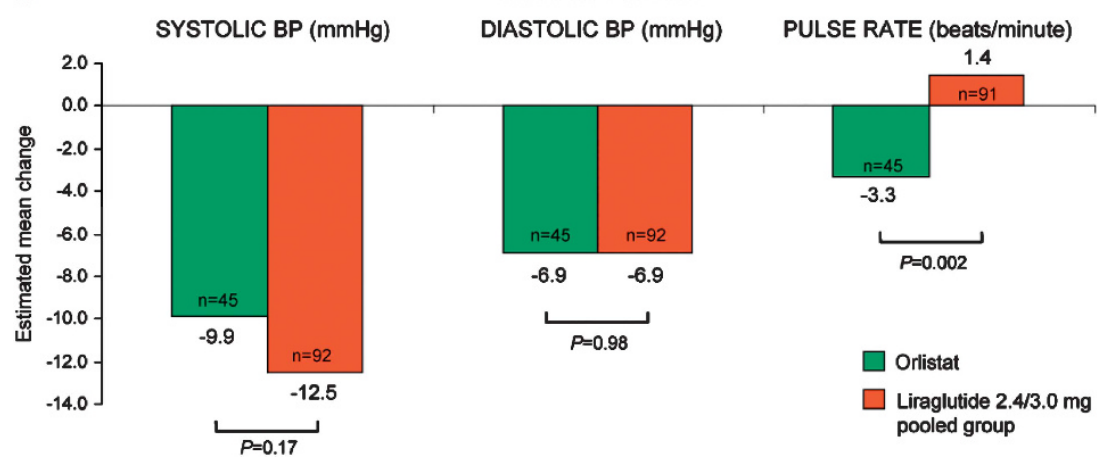

Figure 3. (b) (pulse data only).

Supplementary Information accompanies the paper on International Journal of Obesity website (http://www.nature.com/ijo) 